\title{
Sharing and caring for better health
}

\author{
Fiona Godlee editor in chief
}

The BMJ

At your last medical scientific conference were you encouraged to tweet? And would you have been surprised if the organisers had asked you not to? Delegates at the American Diabetes Association scientific meeting in June found themselves in that position, being asked not to share photographs of presented slides through social media. As Dara Mohammadi explains (doi:10.1136/bmj.j3966), many delegates turned to Twitter to question the ADA's draconian approach-more indeed than had been tweeting the conference proceedings.

The episode raises questions about what such conferences are for. Are they for researchers to share their work so that others can celebrate, critique, and build on it for the good of patients and the advancement of medical science? Or are they for making money for the organisers? (In which case limiting any sharing of information to those who pay to attend makes perfect sense.) The ADA is reviewing its rules and says that the ban was to protect intellectual property. But the provenance of ideas aired and then shared on social media should be abundantly clear, and organisers could ask delegates to ensure they give proper attribution by creating a conference twitter handle. Most journals' policies are now social media friendly. Conferences should be too.
The NHS was at the centre of its own extraordinary Twitter storm over the summer, with heated 140 character exchanges between NHS super-user Stephen Hawking and the man responsible for what Hawking said was a disastrous move towards a US style system: Jeremy Hunt, England's health secretary (doi:10.1136/bmj.j4007). I leave it to you to decide who won the war of words, scientifically, politically, and in the eyes of the public.

This week a true NHS grandee, Nigel Crisp, shares his thoughts on the future of the service (doi:10.1136/bmj.j3895). Crisp is the only person to have been chief executive of the NHS in England and the Department of Health's senior civil servant, so his views are worth reading. Healthcare is not just a cost, he says: it brings the country huge social, scientific, and economic benefits. But any health system will be sustainable only if it is understood to be one part of a wider health generating project in which all sections of society must play their part. Above all, to survive and flourish, healthcare needs political and public support.

A $B M J$ series on what makes a sustainable health service is in the works. Meanwhile, please share your thoughts, through Twitter and our rapid responses. 